\title{
Studies on Conditioned Responses in Fishes. Part III. Wave-length Discrimination in Blennius pholis $\mathrm{L}$.
}

\author{
By \\ Herbert 0. Bull, Ph.D., \\ The Dove Marine Laboratory, Armstrong College, University of Durham.
}

Contents.

I. Introduction . . . . $\quad 347$

II. Procedure . . . . . . . . . . . . . 348

III. Detailed record of an experiment on a dark-adapted fish illustrating the general nature of the experiments and the progress of "conditioning" and subsequent " differential discrimination". . . . . . . . . 352

IV. Notes and summaries of experiments on individual fishes in each of which a

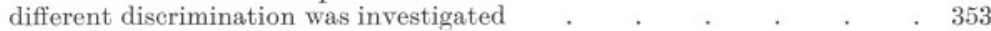

(a) Dark-adapted fishes . . . . . . . . . . . 353

(b) Daylight-adapted fishes . . . . . . . . . . . . . . 361

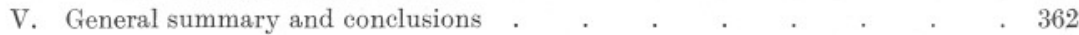

VI. References . . . . . . . . . . . . . . . . . . . 364

\section{Introduction.}

IT has been shown $(1,2)$ that the capacity for building up visual conditioned responses is common to many types of fish when the unconditioned stimulus used as the basis for the "conditioning" is food. Preliminary work at Plymouth, using the fish Blennius gattorugine, showed that it was possible that a knowledge of wave-length discrimination in that species might be acquired by the now familiar method of " conditioning" to an electric shock. This work was continued when I came to Cullercoats, and six specimens were used which were sent from Plymouth in 1929. All of these died within a short space of time during the succeeding winter months, owing to the intense cold. It was therefore necessary to restrict the investigation to Blennius pholis L., which is both plentiful and hardy at Cullercoats. Some progress had already been made and in Part II (2) it was intimated that an analysis would be made of the capacity for wavelength discrimination in Blennius pholis using an electric shock as the unconditioned stimulus. The present paper gives the results of that enquiry as far as it was taken.

The motor response to the electric shock is probably of a truly reflex nature. The responses involved in food-taking are more complex and probably not of the nature of reflexes. This enquiry was thus originally begun with the object of ascertaining primarily whether this type of 
experiment (use of electric shock) was more likely to yield reliable information upon sensory discrimination than that where the unconditioned stimulus was food. The range of wave-lengths investigated is therefore more restricted than it would have been had the investigation into wavelength discrimination been the sole objective. Sufficient ground was covered, however, to show a very wide range of wave-length discrimination in this fish.

In order to establish the evidence of capacity for wave-length discrimination in fishes the light-stimulus must be presented in such a way as to eliminate the possibility that intensity, shape, form, or any other kind of environmental change is being associated with the shock. The intensity factor has been controlled and virtually eliminated in the present investigation by demonstrating that after discrimination has been effected it continues to be shown at varying intensities obtained by raising and lowering the source of light in a closed "light" box as described in more detail below. In the earlier parts of these studies it was found simple and convenient to represent the whole course of an experiment graphically. The general course of learning in these fishes was thus readily portrayed. It is not possible to do this in the present instance in such a way as to illustrate the essential feature involved, i.e. differentiation between one or more wave-lengths and their varying intensities. Owing to the prohibitive cost of printing the detailed histories of these experiments it has been necessary to restrict the detail to one typical "log," and merely to summarise in the present paper the salient features of the remaining experiments in regard to wave-length discrimination. While the results of the different experiments are in general agreement, no two individuals can be said to have reacted identically, although their recorded response was reduced to the simplest possible form - the presence or absence of a bodily movement. Each individual had not only some physical feature rendering it familiar as an individual, but had recognisable idiosyncrasies relating to its general behaviour. General notes relating to the method, the scope of the inquiry, and its relations to wider problems are to be found in Part I (1).

\section{Procedure.}

The methods used have been described in an earlier paper (1) and remain unchanged in their essential arrangement.

Visual stimuli of varying wave-length were obtained by the use of Wratten gelatine light-filters in conjunction with a "Stella" $100 \mathrm{w}$. tungsten filament gas-filled opal lamp operating on a 240 -volt alternating current supply. The lamp was housed in a " light chamber," an elongated box 50 inches long and 5 inches square in section, with a dead-black 
smooth interior surface. The lamp was held by a string passing over the top of the "light chamber," by which it could be raised or lowered, the extent of which movement was measured by a scale on the outside of the box. The lower end of the box was closed by a smooth-running lanternslide carrier accommodating the filters. These were obtained from Kodak Ltd. in the form of plain gelatine films and were then suitably mounted between two cover-glasses of selected quality. The characteristics of the filters used are tabulated in Table I, taken from the Eastman Kodak Co.'s book on "Light filters." The total transmissions are accurate to within $5 \%$, with the exception of Neutral Grey No. 96, which is accurate to within $10 \%$. Under the conditions of these experiments it is unnecessary to calibrate more accurately.

A diffusing screen was placed within the light chamber immediately above the colour filter. This was a fixture throughout the series. The "light chamber" was set up in position over the cabinet housing the fish undergoing "conditioning" so as to be immediately dorsal to a circular opening of 1.5 inches in diameter in the top of the cabinet. The actual visual stimulus as presented to the fish in the vessel within the cabinet was therefore a circle of light immediately above it.

The general disposition of the remaining parts was as described in Part I (1), p. 525. The light and the shock were operated from soft copper knife switches placed at 4 feet distance on thick felt on a separate stand. Disturbances were eliminated as far as possible by carrying out the experiments on the dark-adapted fishes at night; by doing those on daylight-adapted individuals in a locked room; and by covering the floor and the various stands with thick felt. In addition, care was taken to reduce personal activity to a minimum during the course of an actual stimulation. The cabinet housing the fish was light proof when closed for the experiments on dark-adapted individuals. The response was noted by means of a pointer connected to a cover-glass treated so that it floated on the top of the water containing the fish, as described in Part I, p. 525. Movement of the pointer was observed against a white background faintly illuminated by a small electric torch.

The filters chosen for the work on each individual were generally of a closely similar total transmission, in order to avoid any considerable intensity differences from the beginning. It is, however, practically certain that under the conditions of the experiment, very wide differences in intensity can probably be permitted without affecting the issue relating to wave-length discrimination. In this respect they contrast strongly with experiments involving a choice between two contiguous colours or coloured surfaces, or those where a preference is apparently exhibited between coloured compartments, etc. There is, in addition, direct proof in one of the present experiments that this fish does not differentiate 


\section{TABLE I.}

\section{[By permission of Eastman Kodak Co.]}

\section{Physical Characteristics of the Filters used in these Experiments.}

These particulars are those of the makers. The names and the numbers are taken from their catalogue. Immediately beneath the filter number is the approximate value of the total light transmission of each filter (percentage). The columns below this give the percentage transmissions of the light of the wave-length values indicated in the first vertical column, where the wave-lengths are shown in millimicrons. The values given throughout are those for the maker's standard films : particular filters are liable to diverge somewhat from these figures.

\begin{tabular}{|c|c|c|c|c|c|c|c|c|c|c|c|}
\hline Colour of filter & Red & Magenta & Blue & Green & Red & $\begin{array}{l}\text { Orange- } \\
\text { red }\end{array}$ & $\begin{array}{l}\text { Orange- } \\
\text { yellow }\end{array}$ & $\begin{array}{l}\text { - Yellow- } \\
\text { green }\end{array}$ & $\begin{array}{c}\text { Pure } \\
\text { green }\end{array}$ & $\begin{array}{l}\text { Blue- } \\
\text { green }\end{array}$ & $\begin{array}{c}\text { Neutra } \\
\text { grey }\end{array}$ \\
\hline Name of filter & $\begin{array}{l}\text { Stage } \\
\text { red }\end{array}$ & $\begin{array}{l}\text { Minus } \\
\text { green }\end{array}$ & $\begin{array}{l}\text { Dark } \\
\text { tolui- } \\
\text { dine } \\
\text { blue }\end{array}$ & $\mathrm{B}_{2}$ & $a$ & $\beta$ & $\gamma$ & $\delta$ & $\epsilon$ & $\eta$ & - \\
\hline $\begin{array}{l}\text { No. of filter } \\
\text { Total }\end{array}$ & 27 & 32 & $38 \mathrm{~A}$ & 58 & 70 & $71 \mathrm{~A}$ & 72 & 73 & 74 & 75 & 96 \\
\hline smission & $23 \cdot 0$ & $19 \cdot 0$ & $16 \cdot 5$ & $23 \cdot 0$ & 0.6 & $1 \cdot 0$ & $1 \cdot 0$ & $3 \cdot 3$ & $3 \cdot 3$ & 1.5 & vari \\
\hline $\begin{array}{c}\text { Wave } \\
\text { length } \\
\mathrm{m} \mu\end{array}$ & & & & & & & & & & & \\
\hline 400 & - & $42 \cdot 80$ & $33 \cdot 80$ & - & - & - & - & - & - & - & $6 \cdot 72$ \\
\hline 10 & - & $47 \cdot 90$ & $38 \cdot 90$ & - & & - & - & 一 & - & - & $7 \cdot 5$ \\
\hline 20 & - & $53 \cdot 60$ & $\begin{array}{l}43 \cdot 50 \\
46 \cdot 60\end{array}$ & - & - & - & - & - & - & - & $7 \cdot 96$ \\
\hline 30 & - & $60 \cdot 10$ & $\begin{array}{l}46 \cdot 60 \\
49 \cdot 00\end{array}$ & - & - & - & - & - & 一 & - & $8 \cdot 12$ \\
\hline 40 & - & $65 \cdot 10$ & $49 \cdot 00$ & - & - & 一 & - & - & - & - & $8 \cdot 12$ \\
\hline 50 & - & $63 \cdot 10$ & $49 \cdot 60$ & & & - & - & - & - & - & $7 \cdot 96$ \\
\hline 60 & - & $52 \cdot 80$ & $50 \cdot 10$ & - & - & - & - & - & - & $0 \cdot 80$ & $7 \cdot 85$ \\
\hline 70 & - & $40 \cdot 00$ & $49 \cdot 00$ & -- & - & - & - & - & - & $6 \cdot 30$ & $7 \cdot 58$ \\
\hline 80 & - & $26 \cdot 40$ & $46 \cdot 90$ & $1 \cdot 97$ & - & - & - & - & - & $17 \cdot 30$ & $7 \cdot 43$ \\
\hline 90 & - & $13 \cdot 80$ & $43 \cdot 50$ & $11 \cdot 46$ & - & - & - & - & - & $9 \cdot 10$ & $7 \cdot 23$ \\
\hline 500 & - & $3 \cdot 99$ & $39 \cdot 70$ & $30 \cdot 23$ & - & - & - & - & - & $14 \cdot 10$ & $7 \cdot 23$ \\
\hline 10 & - & $0 \cdot 62$ & $36 \cdot 60$ & $50 \cdot 10$ & - & - & - & - & $1 \cdot 00$ & $5 \cdot 00$ & $7 \cdot 23$ \\
\hline 20 & - & - & $31 \cdot 60$ & $60 \cdot 20$ & - & - & - & - & $8 \cdot 00$ & $1 \cdot 30$ & $7 \cdot 23$ \\
\hline 30 & - & - & $27 \cdot 60$ & $54 \cdot 70$ & - & - & - & - & $15 \cdot 10$ & $0 \cdot 31$ & $7 \cdot 58$ \\
\hline 40 & - & - & $73 \cdot 60$ & $39 \cdot 00$ & - & - & - & - & $10 \cdot 00$ & - & $7 \cdot 85$ \\
\hline 50 & - & - & $19 \cdot 50$ & $30 \cdot 20$ & - & - & - & - & $4 \cdot 00$ & - & $7 \cdot 96$ \\
\hline 60 & - & - & $15 \cdot 00$ & $25 \cdot 10$ & - & - & - & $2 \cdot 50$ & $1 \cdot 14$ & - & $8 \cdot 12$ \\
\hline 70 & - & - & $11 \cdot 70$ & $17 \cdot 00$ & - & - & - & $8 \cdot 00$ & $0 \cdot 12$ & - & $8 \cdot 12$ \\
\hline 80 & $1 \cdot 26$ & - & $8 \cdot 30$ & $10 \cdot 00$ & 一 & - & - & $5 \cdot 70$ & - & - & $8 \cdot 12$ \\
\hline 90 & $33 \cdot 00$ & - & $5 \cdot 60$ & $5 \cdot 50$ & - & - & $1 \cdot 14$ & $2 \cdot 68$ & - & - & $7 \cdot 96$ \\
\hline 600 & $61 \cdot 90$ & - & $3 \cdot 70$ & $2 \cdot 80$ & - & - & $3 \cdot 78$ & $1 \cdot 10$ & - & - & $7 \cdot 58$ \\
\hline 10 & $78 \cdot 30$ & $3 \cdot 00$ & $2 \cdot 30$ & $1 \cdot 30$ & - & $1 \cdot 26$ & $4 \cdot 40$ & $0 \cdot 39$ & - & - & $7 \cdot 23$ \\
\hline 2 & $78 \cdot 30$ & $39 \cdot 60$ & $1 \cdot 50$ & $0 \cdot 57$ & - & $7 \cdot 10$ & $2 \cdot 86$ & $0 \cdot 15$ & - & - & $7 \cdot 08$ \\
\hline 3 & $78 \cdot 30$ & $67 \cdot 50$ & $0 \cdot 96$ & $0 \cdot 21$ & - & $9 \cdot 80$ & $1 \cdot 51$ & - & - & - & $6 \cdot 93$ \\
\hline 40 & $78 \cdot 30$ & $79 \cdot 40$ & $0 \cdot 62$ & - & - & $10 \cdot 00$ & $0 \cdot 78$ & - & - & - & $6 \cdot 93$ \\
\hline 50 & $78 \cdot 30$ & $79 \cdot 40$ & $0 \cdot 52$ & - & $1 \cdot 00$ & $9 \cdot 20$ & $0 \cdot 37$ & - & - & - & $6 \cdot 93$ \\
\hline 60 & 30 & $79 \cdot 40$ & 0.42 & - & $10 \cdot 00$ & $8 \cdot 00$ & $0 \cdot 37$ & - & - & - & $6 \cdot 93$ \\
\hline 70 & $78 \cdot 30$ & $79 \cdot 40$ & $0 \cdot 4$ & - & $\cdot 10$ & $7 \cdot 10$ & $0 \cdot 49$ & - & - & - & $7 \cdot 23$ \\
\hline 80 & & $79 \cdot 40$ & $0 \cdot 3$ & - & 80 & $6 \cdot 60$ & $1 \cdot 24$ & $0 \cdot 15$ & - & - & $7 \cdot 30$ \\
\hline 90 & & $79 \cdot 40$ & $0 \cdot 3$ & $0 \cdot 10$ & & $6 \cdot 70$ & & $2 \cdot 18$ & - & $0 \cdot 10$ & $7 \cdot 58$ \\
\hline 700 & $79 \cdot 40$ & $79 \cdot 40$ & $0 \cdot 37$ & $0 \cdot 73$ & $74 \cdot 50$ & $8 \cdot 00$ & $11 \cdot 50$ & $6 \cdot 30$ & - & $0 \cdot 24$ & $7 \cdot 85$ \\
\hline
\end{tabular}


between very wide differences in intensity of grey. Apart from this, the intensity factor was eliminated by adjustment of the height of the lamp above the diffusing screen at successive trials in such a way that the colour being discriminated was at times relatively brighter or duller than the primary conditioning stimulus and passed through all intermediate conditions.

A standard scale of distances of the several parts of the lighting arrangement was adopted for the primary conditioning colour in each instance. This intensity is spoken of as " threshold " intensity throughout, and was equivalent at the point where the filter interrupted the light to an illumination of approx. 10,000 metre-candles.

With two exceptions (specimens $\mathrm{A}$ and $\mathrm{B}$ ) the routine of the daily procedure was the same throughout. The specimen was taken from the laboratory tanks and placed carefully in the experimental apparatus at an interval varying from 15 to 60 minutes before the first " signalling " stimulus of the day. It was then given a succession of " signalling" stimuli, usually at intervals of 5 minutes. The number of these ranged from 5 to 10 per day. After a further interval of not less than 15 minutes the fish was taken out and returned to its normal environment in the laboratory tanks. At the same time if more than one was being investigated, another fish was placed in the apparatus, and so on until the daily routine was completed. In the early stages of each individual's record the "signalling" stimulus was constantly associated with an electric shock given shortly after. Such stimuli were, therefore, "conditioning", stimuli. After a number of such associations these stimuli were found by themselves to evoke the bodily movement originally associated with the shock. Thus a conditioned response was established.

A second "signalling" stimulus with different optical properties was then introduced in irregular sequence, but at no time was this one associated with a succeeding shock. The light was allowed to act for the whole of the interval between "signalling" and "shock" when using the conditioning stimulus, and for one minute or longer when using the contrasting stimulus. (All presentations of the contrasting stimulus are italicised in the representative table.)

All the specimens used were of full adult size.

Different wave-lengths were used for the discriminations in each one of the individuals used. The fish were known by a distinctive letter and the results are summarised for convenience under these letters. The summaries show the full nature of the wave-length discriminations investigated, and give the salient features relating to this point. A detailed record of one of the experiments as a typical example of procedure is given in the next section, and all are summarised in Section IV.

The full records of the experiments will be deposited in the British 
Museum (Natural History) in accordance with the scheme for the deposition of lengthy tabular matter too extensive for complete publication. They may be consulted there on application to the Director, British Museum (Natural History), South Kensington, London, S.W. 7.

III. Detailed Record of AN Experiment on a DARK-ADAPted Fish ILLUSTRATING THE GENERAL NATURE OF THE EXPERIMENTS AND THE PROGRESS OF " CONDITIONING" AND SUBSEQUENT "DIFFERENTIAL DISCRIMINATION."

This typical record (Table II) shows the details of the experiment where one intensity of grey was used for conditioning, and subsequent discrimination was studied for other intensities of grey. It has already been shown that Labrus bergylta (1, pp. 513-9) does not discriminate comparatively wide differences in intensity of a light source. Blennius pholis and Labrus bergylta both predominantly seek for food, etc., by sight so far as may be ascertained by ordinary observation of their behaviour. A demonstration that Blennius pholis likewise could not discriminate between wide differences in intensity would support any positive evidence of wave-length discrimination which might be derived from other experiments in this series, regardless of any precaution which might have been actually taken to ensure that intensity was not the discriminated factor. The record shows conclusively that this is actually so. The fish was positively conditioned to Neutral Grey (No. 96), with a total transmission of $25 \%$, and with the light at "zero" position ("Threshold" intensity as defined on p. 351). This is equivalent to an intensity of approximately 20,000 metre-candles at the diffusing screen. This conditioning stimulus preceded the shock by 2 seconds. The detailed "log " is shown in Table II.

A suggestion of "conditioning" appeared at the 25th-28th trials (Dec. 16th), but no further evidence of it was seen until the 75th trial on January 14th, from which date it remained constant. It may be noted that during the period December 21st to January 8th no experiments were made. From January 15th onwards this fish was given repeated trials (interspersed with typical conditioning) of a number of other intensities of grey. These were obtained as already stated by raising the light source to varying heights above the diffusing screen, and are all italicised in the table (i.e. trials No. 82, 85, 87, Jan. 15th). It will be seen that throughout the remainder of the investigation on this fish all intensities down to $(0 \cdot 0017 \times$ Threshold $)$ evoked fairly uniformly a sharp motor response differing in no apparent respect from the conditioned response elicited by the primary conditioning intensity. Absence of 
movement occurred consistently only with an intensity of $0.00098 \times$ Threshold, which is equivalent to approximately 20 metre-candles.

It appears certain, therefore, that under the conditions of these experiments Blennius pholis cannot discriminate such small intensity differences as exist between the colour filters used in the other individuals. The reason for the insistence on this point is the more readily appreciated by confining oneself in a dark room and attempting to state the comparative brightness of the same circle of light produced under the same conditions.

This is found to be extremely difficult, whilst the colours used in these experiments are readily distinguished as such by human beings with normal vision, regardless of enormous variations in intensity.

It needs to be emphasised that Table II is more than a mere catalogue of experiments similarly performed on the same animal, but at different times. It portrays the orderly development of a conditioned motor reaction in response to the stimulus of a grey light signal; it then demonstrates that when this is firmly established a great reduction in the intensity of the light signal has no effect on the appearance of the response beyond the fact that if a large number of trials are made without succeeding shock (as at trials 154 to 159), the original response to the primary conditioning stimulus may be weakened. In such an instance a single reinforcement is sufficient to cause its return to its original strength.

IV. Notes aND SUMmaries OF EXPERIMENTS ON INDIVIDUAL FISHES IN EACH OF WHICH A DIFFERENT DISCRIMINATION WAS INVESTIGATED.

(a) Dark-adapted fishes.

Specimen A. The Discrimination of unfiltered "white" light" from green.

It has been already stated that the general routine of these experiments was to take the fishes out of the aquarium tanks some time before a series of conditioning trials and to replace them after the day's work. This specimen (as also was Specimen B) was confined to the completely dark apparatus for the duration of the whole experiment, from March 12th to May 22nd. The fishes lived apparently healthily and contentedly and it was noted that they took food on occasion at the same time as a shock was given, thus showing its relatively innocuous nature.

The primary conditioning stimulus was Wratten filter No. 58, B2, green, transmitting mainly $490-580 \mathrm{~m} \mu$, with a total transmission of $23 \%$, preceding the shock by 3 seconds.

The fish was given no visual stimuli until April 6th. It was then thoroughly tested with the green light alone, unaccompanied by shock,

\footnotetext{
* The colour of the light of a tungsten filament gas-filled opal lamp whilst ordinarily spoken of as "white" has in fact a saturation of $56 \%$, and a "hue " of approximately $586 \mathrm{~m} \mu$.
} 


\section{TABLE II.}

\section{"LoG" of Experiment on Specimen F. (Blennius pholis).}

The columns in order from left to right show :

1. Date and times when specimen was put into the apparatus (the flrst-mentioned) and taken out again at the conclusion of each day's work (the last-mentioned): the times in brackets. Continental timing throughout (24-hour system).

2. The times of each association or trial.

3. The serial number of each association or trial.

4. Nature of the stimulus used. The positive " conditioning " stimulus for the establishing of the conditioned response was Neutral Grey, filter No. 96 used at "zero" distance from the sereen as explained in text (p. 351). This is called "Threshold," and all trials with this are shown in plain type.

The differential stimuli of lower intensities of grey are shown as fractions of the primary intensity, and all such trials are shown in italies.

5. The nature of the response to the stimulus named in 4.

6. The shock-reaction. This is noted to show that upon each occasion of giving the positive stimulus, a shock followed and caused a reaction (except for occasional trials when no shock was given for test purposes) ; all the intensities below threshold were not followed by shock, and the note is made " No $\mathrm{S}$. given."

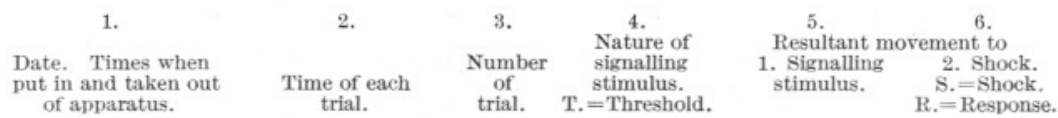

Dec. 9 [18 50 ; 1940$]$

$1905,08,11,14,17,1$ to 8 Grey. T. None

Dec. 10-11. No expts.

Dee. 12 [17 00; 17 36]

Dec. 13. No expts.

Dec. 14 [21 20; 2145$]$

Dec. 15. No expts.

Dec. $16[2040 ; 2120]$

$$
20,25,30
$$
$1717,20,23,26,28,9$ to 14

$2130,32,34,36,38,15$ to 21

$$
40,42
$$

$2053,56: 2100 \quad 22$ to 24

2103

2106

2110

2112

25
26
27
28

Dec. 17. No expts.

Dec. 18 [17 05; 1756$]$

$1720,23,26,30,34,29$ to 36 $38,42,46$

Dec. 19 [21 05 : 22 10]

Dec. 20 [18 25; 19 30]

$2120,25,28,30,35,37$ to 46 $40,45,50,2200$

$1840,43,46,50,55 ; 47$ to 56 $1900,03,06,10,15$

Dec. 21 to Jan. 8. No expts.

Jan. 9 [16 55; 18 00]

Jan. 10-12. No expts. Jan. 13 [21 00; 22 00]

Jan. 14 [21 05 ; 22 50]

$$
35,40,45
$$

$2115,20,25,30,35,65$ to 71

$$
40,45
$$

$2120,25,30$

2135

2140

2145

2150

2220

Jan. 15 [18 35; 1940 ]

1850,55

1900

1905

1910

1915

1920

1925

Jan. 16-19. No expts.

1615

Jan. 20 [16 00; 1655 ]

1615
1620

1625

1630

1635

1640

Jan. $21[2125: 2210]$

\begin{tabular}{|c|c|}
\hline & \\
\hline 72 to 74 & ". \\
\hline 75 & ," \\
\hline 76 & .. \\
\hline 77 & . \\
\hline 78 & . \\
\hline 79 & ", \\
\hline${ }_{82}^{80.81}$ & $0.00 \ddot{098} T$. \\
\hline 83 & T. \\
\hline $\begin{array}{l}84 \\
85\end{array}$ & $\ddot{0.0039 ~ T . ~}$ \\
\hline 86 & \\
\hline 87 & $0.0156 \mathrm{~T}$ \\
\hline 88 & $\mathrm{~T}$. \\
\hline 89 & , \\
\hline 90 & . \\
\hline 91 & $0.00098 \mathrm{~T}$. \\
\hline 92 & $0.0039 \mathrm{~T}$. \\
\hline 94,95 & T. \\
\hline 96 & $0 \ddot{0} \cdot 00098 \mathrm{~T}$. \\
\hline 97 & $0.0039 \mathrm{~T}$ \\
\hline 98 & T. \\
\hline
\end{tabular}

Distinct at $15^{\circ}$

None

Sharp at $1.5^{\circ}$

None

,

Strong at once

$\ddot{1} \ddot{*}$.

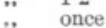

$\because \ddot{*}=$

None in $30^{\circ}$

Strong at once

None in $30^{\circ}$

Strong at once

Strong at $0.8^{*}$

None in $2^{*}$

strong at once

None in $30^{\prime \prime}$

Strong at $3^{\prime \prime}$

Strong at $1 \cdot 2^{\prime \prime}$

None in $30^{\circ}$

Strong at once
Strong R.

*

,

*

*

No $\ddot{S}$, given.

Strong R.

No $\mathrm{S}$. given.

No $S$. given.

Strong $\mathrm{R}$.

No $S$. given.

Strong $\mathrm{R}$.

".

No $\ddot{S}$. given.

Ströng R.

No $\ddot{S}$. given.

Strong R. 
1.

Date. Times when put in and taken out of apparatus.

Jan. 22. No expts.

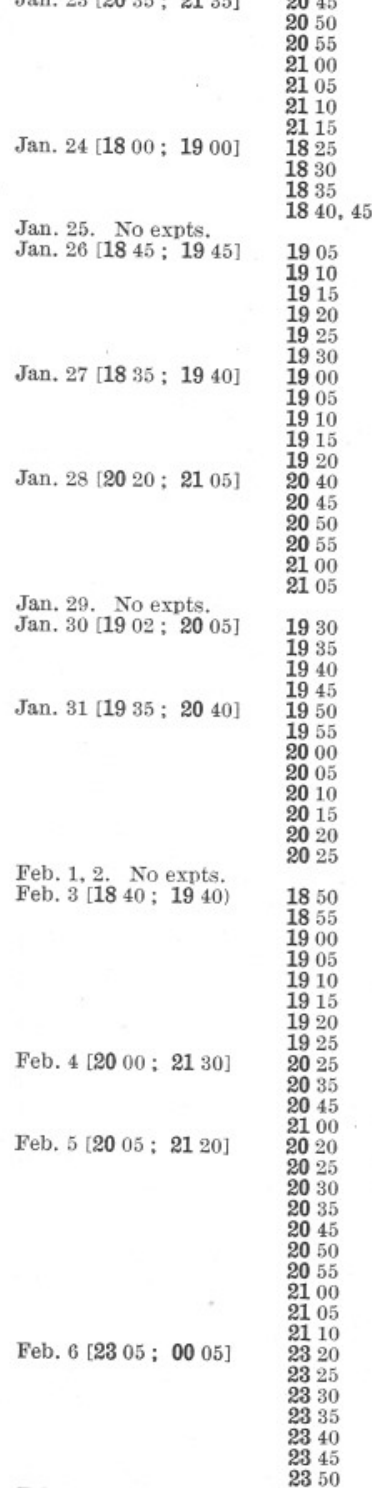

Feb. 8. Accidental death of animal.

\section{2.}

Time of each trial.

$\begin{array}{lr}45 & \\ 50 & 1 \\ 55 & 1 \\ 00 & 1 \\ 05 & 1 \\ 10 & 1 \\ 15 & 1 \\ 25 & 1 \\ 30 & 10 \\ 35 & 10 \\ 40,45 & 109,\end{array}$

9,110

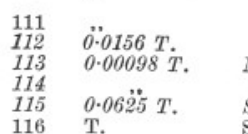

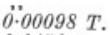
$0.0156 \mathrm{~T}$. $0.0039 \mathrm{~T}$.

$\mathrm{T}$. T.00098 $\mathrm{T}$. T. $00098 \mathrm{~T}$. $0.0039 \mathrm{~T}$. T.$$
\text { " }
$$

\section{$0.0156 \mathrm{~T}$} $0.00098 \mathrm{~T}$. T.

"

,.

o:00098 T. $0.0039 \mathrm{~T}$ 0.00098 T. $0.0039 \mathrm{~T}$

T.

,.

$0.0039 \mathrm{~T}$ T.

$0.0039 \mathrm{~T}$ $0.00098 \dot{T}$. $\mathrm{T}$. $0.0017 T$. $\mathrm{T}$. T.0039 $\mathrm{T}$. $0.00098 \mathrm{~T}$. T.

0.0039 T. $0.00098 \mathrm{~T}$. T. 0.0625 T. $0.0156 \mathrm{~T}$. $0.0039 \mathrm{~T}$. $0.00098 \mathrm{~T}$ $0.00098 \mathrm{~T}$
$0.0039 \mathrm{~T}$. 0. T.

.

",

\subsection{9} $0.00098 \mathrm{~T}$ $0.0017 T$. 0.0017
0.0039
$T$ T.
5. Resultant movement

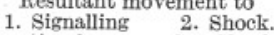
stimulus. $\mathrm{S}$. = Shock. R. $=$ Response.

None in $2^{\circ}$ Strong at $3.0^{\prime \prime}$ . $1 \cdot 2^{\prime \prime}$ strong at $1.6 "$ Strong at $1 \cdot 6$ None in $30^{\prime \prime}$ Strong at once
None in $2^{\prime \prime}$ slight at $0.2^{\prime \prime}$ Strong at once

, $0.4^{\prime \prime}$ None in $30^{\circ}$ Ströng at $\ddot{1} \cdot 4^{\prime \prime}$ Strong at $1 \cdot 8^{\prime \prime}$

None in $30^{\circ}$ Strong at $1 \cdot 6^{\prime \prime}$ Distinct at once Distinct at one Distinct at once Strong at once Strong at once
None in $30^{\circ}$ Distinct at 5." Strong at $0.8^{\prime \prime}$

$$
\text { . } 1.2^{\prime \prime}
$$

Sharp at once. None in $30^{\circ}$ Strong at once.$$
\text { , }
$$$$
\text { ." }
$$

None in $30^{\circ}$

Sharp at once

None in $30^{\circ}$ Distinct at 2 "

strong at $\ddot{2}^{\prime \prime}$

Sharp at once Strong at $0 \cdot 8^{\prime \prime}$ Strong at $1.4^{\circ}$ None in $30^{\prime \prime}$ Strong at once Distinct at $3^{\circ}$ Nome in $30^{\circ}$ Strong at once Strong at once

None in $30^{\circ "}$ Strong at $0.6{ }^{\circ}$ Strong at $\theta^{\circ} 6^{\prime \prime}$ None in $30^{*}$ Strong at once Strong at once ". "

None in 30"

Distinct at once Shary at once None in $2^{\prime \prime}$ Strong at once

$$
\text { ", }
$$

strong at " None in $30^{\circ}$ Leisurely at 20 Sharp at 5. Sharp at 5.
Strong R.

No S. given.

$$
\text { ". }
$$

Strong $\mathrm{R}$.

No S. given.

No $\ddot{\mathrm{S}}$. given. Strong $\mathrm{R}$.

,

No "̈. given.

",

Strong $\mathbf{R}$.

No "S. given.

",

Strong $\mathrm{R}$.

No S. given.

Strong $\mathrm{R}$.

No S. given.$$
\text { , }
$$

Strong $\mathrm{R}$.

No S. given.

".

Strong $\mathrm{R}$.

No S. given.

Strong R.

No S. given.

"

,

Ströng R.

No S. given.

Strong R.

No S. given.

Ströng $\mathrm{R}$.

No $S$. given.

Strong R.

No S. given.

Ströng R.

No S. given.

Strong R.

No $S$, given.$$
\text { ,. }
$$

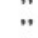

Ströng $\mathrm{R}$.

No $\mathrm{S}$. given.

Ströng $\mathrm{R}$.

No $S$, given.

$$
\text { ,", }
$$

No $\ddot{s}$. given 
at irregular intervals between the hours of 2000 and 2130 on April 6th ; and between three similar intervals on the three succeeding days; for a total of 50 such trials. No movement occurred in response to any of these presentations. These preliminary presentations were made in all these experiments, and no further specific mention of them is made.

The association of light with succeeding shock was begun on April 10th. Eighty-nine such associated presentations were required before the appearance of a conditioned motor response. This occupied a period of 14 days of actual experiment in a total of 27 days, with an average of 6.7 trials per day of actual experiment. At trial 105 the differential stimulus of unfiltered "white " light unadjusted for intensity was allowed to act for 2 minutes, without succeeding shock. No movement resulted. The same result was obtained with each presentation of the unfiltered light until the conclusion of the experiment at the 183rd trial on May 22nd, regardless of the intensity which was on occasions equated and at times varied considerably.

This fish showed a complete discrimination between the green light and a wide range of intensities of unfiltered "white" light without the necessity for differential conditioning.

Specimen B. The discrimination of unfiltered "white" light from magenta.

The conditions for this individual were the same as those for Specimen A. The primary conditioning stimulus was Wratten filter No. 32 (Minus Green 3), transmitting from $400-500$ and $600-700 \mathrm{~m} \mu$, with a total transmission of $19 \%$, and, as in A, preceded the shock by 3 seconds.

The fish was placed in the apparatus on May 13th and fed and tended, without experiments of any kind until June 1st. After preliminary tests, conditioning was begun on June 4th. A well-defined conditioned motor response was first obtained in response to the magenta light at the 21st trial on the 3rd day of actual experiment. The differential stimulus of " no filter " was first given after the 31st primary conditioning association, and as in Specimen A produced no resultant movement, either during the 2 minutes for which it was allowed to act or during the succeeding 3 minutes of darkness before the next trial. No conditioned movement was obtained with " no filter" at any time in the whole course of the experiment, which was concluded after 103 associations on June 21st. The conclusion was premature owing to the accidental death of the animal, but this fish showed a complete discrimination of the unfiltered light from the magenta regardless of intensity from the commencement, and, as in A, no differential conditioning was required to establish it. 


\section{Specimen C. The discrimination of magenta from red.}

Primary conditioning stimulus the same as for B, i.e. Wratten filter No. 32, preceding the shock by 5 seconds. Conditioning was begun on December 5th and the experiment concluded on January 21st after 132 trials.

Movement in response to the conditioning stimulus occurred erratically in the earlier stages, isolated responses being elicited at the 15th, 26th, and 47th trials ; more certain indications of conditioning occurred on the 12 th day at trials 54, 55, 56, and again on the following day at the 64th and 65 th ; trials 72 to 75 gave positive responses, but the following three negative. From the 79th trial to the conclusion a typical conditioned motor response followed every presentation of the " magenta" colour stimulus. Wratten filter No. 27 (Stage Red), transmitting 580-700m $\mu$, with a total transmission of $23 \%$, was first given at trial 83 as a differential stimulus not followed by shock. At the first three presentations with this stimulus an immediate strong response was recorded apparently differing in no respect from that which was being constantly elicited by the magenta light. At the succeeding trial (86) no movement occurred and from then until the conclusion magenta was uniformly discriminated from red, the former constantly eliciting response, the latter producing no response. The total transmission of these two filters is closely alike $(19 \%$ and $23 \%$ ) ; any difference in intensity resulting from this slight difference may be safely ignored in the circumstances of these tests. Nevertheless, slight variations in intensity were made in order to eliminate this possibility.

Specimen D. The capacity for discrimination of red from magenta, grey, and blue, neutral grey from red and blue, and monochromatic orange-red from orange-yellow.

Several aspects of the conditioning process were investigated in this individual. In the first part, from December 12th to January 21st, the objective and procedure was similar to that of the preceding specimens The fish was positively conditioned to filter No. 27 (Stage Red). The conditioning began on December 12th, the light preceding the shock by 2 seconds. Sharp and immediate movement in response to the conditioning colour first appeared at the 21 st trial on the 3rd day of actual experiment. From then until the 84th trial (January 13th) it was elicited fairly consistently. There were no experiments between December 21st and January 12th, a total of 23 days. On resuming on January 13 th the first two trials failed to produce a response, but the succeeding trials showed a positive result indicating the stability of the response over the period of absence. Discrimination between the positive conditioning stimulus and 
the differential stimuli of grey, magenta, and blue, was also shown during this period. From the 85th trial (January 15th) to the 103rd trial (January 20th) the response to the positive conditioning stimulus was, however, very erratic and failed to appear on most of the occasions when it was presented. This was definitely correlated with the fact that the fish was a female with rapidly maturing gonads at the time the experiment began and that the eggs were laid on January 17th. The effect of pregnancy on these responses was repeatedly noticed in Part 1 of these studies. When the fish had recovered and was again feeding readily the conditioned response regained its previous strength and constancy. In the first portion it was established that although the primary conditioning stimulus itself was erratic in its results owing to the reasons mentioned, there was good evidence of discrimination between this and the following :-

Magenta. Wratten filter 32, particulars in preceding sections.

Grey. Wratten filter 96, transmitting from $400-700 \mathrm{~m} \mu$, with a total transmission of $25 \%$.

Blue. Wratten filter $38 \mathrm{~A}$, transmitting mainly $400-550 \mathrm{~m} \mu$, with a total transmission of $16 \cdot 5 \%$.

In the second portion, lasting from January 23rd to February 13th, the possibility was investigated of forming a conditioned response to two separate colours over the same period. For this purpose the original conditioning stimulus of Part 1 (Stage Red) was continued, and on no occasion failed to evoke a positive response. For the second colour Dark Toluidine Blue (38A) was used, which, although it had inhibitory properties in Part 1, readily came to act as a second conditioning stimulus. This dual procedure appears to have exercised considerable influence over the capacity to discriminate other colours. Magenta (32), which was still given constantly without a succeeding shock, uniformly evoked a positive response. Neutral Grey (No. 96), previously also "inhibitory," evoked a positive response at 12 out of 29 presentations. But to consider these figures solely as totalities is misleading, and reference should be made to the full tabular history.

It is necessary in each instance to study each day's record carefully, as in the following example from this time.

Record of February 12TH (column headings and explanations as in Table II).

Feb. $12[2225 ; 2330]$
2.

2240
2245
2250
2255
2300
2305

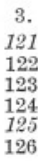

4.

Grey (No. 96) None in $15^{\circ}$ Blue (No. 38A) Strong at once Rë (Nö. 27 Grey (No. 96) Red (No.27) Strong at once
No S. given.

Strong R'.

No"S. given. 
Blue and red were the positive stimuli and grey was the discriminated stimulus which was never followed by shock. The primary object of this part was, however, not concerned with wave-length discrimination, and the matter was not further investigated.

Between February 13th and April 13th, a total of 60 days, no further tests were made with this fish. On starting again, only 11 trials were required to evoke the conditioned response to the blue, while to the more firmly established stimulus of "Stage Red," the response was evoked at its first presentation on April 16th, showing a retention for 63 days.

After this brief test for retention of the conditioned response, a further discrimination was attempted with two colours of much lower intensity and more restricted wave-length. Orange-red, monochromat (filter $71 \beta$ ), $620-700 \mathrm{~m} \mu$ was used as the primary stimulus, with shock following at 3 seconds interval. Nine associations were required to evoke a conditioned response. At the 26th trial, orange-yellow monochromat (filter $72 \gamma$ ) was introduced, at no time reinforced. At its first presentation it gave a positive response similar to that given to filter 71. After 5 such positive reactions it produced consistently negative responses up to the conclusion of the experiment, showing a very clear evidence of discrimination between these two closely allied regions of the spectrum.

\section{Specimen E. The discrimination of blue from magenta and grey.}

This fish was a large female carrying eggs and in similar condition to Specimen D. The conditioning stimulus was Dark Toluidine Blue, filter $38 \mathrm{~A}$, transmitting mainly from $400-550 \mathrm{~m} \mu$, with a total transmission of $16.5 \%$. For the first 130 associations this was given at an interval of one second before the shock. Motor response, apparently " conditioned" in nature, first appeared at the 31st trial on the 4th day of actual experiment, but it remained erratic in appearance. This was found to be due to the superimposition of the response to the shock upon the incipient true conditioned response, so that the latter could not be seen as such. From the 131st trial onwards the interval between stimulus and shock was lengthened to 3 seconds, and no further difficulty occurred.

The discriminating stimuli were magenta, filter 32, and Neutral Grey, filter 96 , these being allowed to act for periods varying from 5 seconds to 120 seconds. Particular attention was paid in this specimen to the possibility of movement occurring after these stimuli ceased to act. This was not found to occur.

Both the magenta and grey were discriminated from the blue with exceptional clearness, grey being presented 27 and magenta 37 times during the course of the total of 217 trials covering the period December 12th to February 11th. With each of these colours a positive response was only given at the first presentation ; thereafter they were ineffective. 
As in Specimen D some disturbance in the course of conditioning was correlated with the deposition of eggs, but was much less marked.

A brief test for "experimental extinction" from the 137th to 145th trials showed that it could be brought about by 7 presentations of the conditioning stimulus if this was not succeeded on each occasion by shock. One single reinforcement by a shock was adequate for its re-establishment.

A series of parallel experiments on this individual when daylight adapted was begun on January 20th (see later).

Specimen $F$. The discrimination of different intensities of neutral grey.

(Recorded in full in Section III, Table II.)

Specimen $G$. The discrimination of monochromatic red from monochromatic yellow-green and pure green.

The conditioning stimulus was Wratten filter No. 70, transmitting $650-700 \mathrm{~m} \mu$ with a total transmission of $0 \cdot 6 \%$.

The discriminatory stimuli were filter No. 73 (Yellow-green), transmitting 560-620m $\mu$, and No. 74 (Pure Green), transmitting 510-570m $\mu$. Both of these had the same total transmission of $3 \cdot 3 \%$.

The conditioning stimulus acted for 3 seconds and the differential stimuli for 120 seconds.

The first conditioned reaction occurred at the 44th trial, and remained fairly stable to the conclusion of the experiment. The evidence for capacity to discriminate the differential stimuli from the positive conditioning stimulus was not so clear as in others, judged numerically. Up to the 87th trial no indication of discrimination could be obtained. Thereafter, whilst in some instances movement occurred to both green and yellow-green, the movement was very different in nature from that given to the positive stimulus of red, being slow and leisurely and contrasting sharply with the quick conditioned reactions. The experiment occupied from April 7th to May 6th, with a total of 126 trials.

Specimen H. The discrimination of magenta from grey, red, green, and blue.

The positive conditioning stimulus was magenta (filter No. 32).

The differential stimuli were as follows :-

Stage Red (No. 27).

Dark Toluidine Blue (No. 38A).

Green (Minus Red, No. 58), transmitting 490-590m $\mu$; total transmission $23 \%$.

Neutral Grey (No. 96) of three different densities :-

Density $2 \cdot 0$. Total transmission $1 \cdot 0 \%$.

$\begin{array}{llllr}, & 1 \cdot 5 . & , & & \\ , & 0 \cdot 6 . & , & & 3 \cdot 2 \%\end{array}$


The positive conditioning stimulus preceded the stock by one second; the discriminatory stimuli acted for 120 seconds. The experiment began on January 12th and was completed on April 24th, after a total of 320 trials.

Conditioned motor response was first obtained at the 21st trial on the 6th day of actual experiment, but was not stable until after the 39th trial. From the 40th trial to the conclusion of the experiment, a wellmarked positive response was given to the positive conditioning light (magenta) upon 126 out of 138 presentations. The occasions when no response occurred were confined solely to those tests which were the first of those made on several different days. Evidence of discrimination, irrespective of intensity variations, was obtained with all the differential colours (constantly presented without shock). This was most clear for neutral grey, with $100 \%$ negative responses (to all its densities and intensities) after the first three presentations. For the other colours the evidence is not satisfactory when examined as numerical totals, but is quite clear upon inspection of the daily behaviour. These colours usually evoked a positive response at their first trial of the day, but successive presentations upon the same day were followed by no response, whilst the primary positive stimulus presented next in sequence was found to yield a strong response. Such behaviour shows undoubted evidence of discrimination. The following extract from the log of a typical day's trials illustrates this point :-

[Explanatory notes as for Table II.]

\begin{tabular}{|c|c|c|c|c|c|}
\hline & 2. & 3. & $\begin{array}{l}4 . \\
\text { Nature of }\end{array}$ & \multicolumn{2}{|c|}{$\begin{array}{cc}5 . & 6 . \\
\text { Resultant movement to }\end{array}$} \\
\hline $\begin{array}{l}\text { Date. Times when } \\
\text { put in and taken out } \\
\text { of apparatus. }\end{array}$ & $\begin{array}{l}\text { Time of each } \\
\text { trial. }\end{array}$ & $\begin{array}{c}\text { Number } \\
\text { of } \\
\text { trial. }\end{array}$ & $\begin{array}{l}\text { signalling } \\
\text { stimulus. }\end{array}$ & $\begin{array}{l}\text { 1. Signalling } \\
\text { stimulus. }\end{array}$ & $\begin{array}{l}\text { 2. Shock. } \\
\text { S.=Shock. } \\
\text { R.= Response. }\end{array}$ \\
\hline \multirow[t]{9}{*}{ April $2[2005 ; 2140]$} & 2020,2025 & 251,252 & Magenta & \multirow{3}{*}{$\begin{array}{l}\text { Strong at once } \\
\text { Moderate at once. } \\
\text { no further in } 120^{\circ}\end{array}$} & \multirow{2}{*}{ Strong $\mathrm{R}$} \\
\hline & 2030 & 253 & 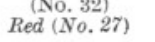 & & \\
\hline & 2035 & 254 & ", & & $\begin{array}{c}\text { No } S . \\
\text {,. }\end{array}$ \\
\hline & $\begin{array}{l}2040 \\
2045\end{array}$ & $\begin{array}{l}255 \\
256\end{array}$ & Magenta & 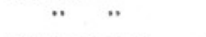 & " \\
\hline & 2050 & 257 & $\begin{array}{l}\text { No. 32) } \\
\text { Grey (No.96) }\end{array}$ & $\begin{array}{l}\text { Strong at once } \\
\text { None in } 120^{\circ}\end{array}$ & \multirow{2}{*}{$\begin{array}{l}\text { Strong R. } \\
\text { No. S. }\end{array}$} \\
\hline & 2055 & & $25 \%$ transmi & & \\
\hline & $\begin{array}{l}2055 \\
2105\end{array}$ & $\begin{array}{l}200 \\
259\end{array}$ & $\begin{array}{l}\text { Blue }(\text { No. } \\
\text { Green (No. } 58)\end{array}$ & $\ddot{~}$ & $\ddot{.}$ \\
\hline & 2110 & 260 & Magenta & & \\
\hline & & & (No. 32) & Strong at once & Strong R. \\
\hline
\end{tabular}

\section{(b) Daylight-adapted fishes.}

Specimen E. Continuing the investigation on Specimen E. The discrimination of green from red.

This individual was used for this experiment when it was already well " conditioned" to a visual stimulus under scotopic (dark-adapted) conditions. No essential departures from the method were made, except for 
the general conditions required for carrying out the tests in diffuse daylight. The positive conditioning stimulus was red (Stage Red, filter No. 27), preceding the shock by 3 seconds. The differential stimulus, green (No. 58), was allowed to act for 30 seconds. The experiment lasted from January 20th to February 10th.

No effect of the preceding scotopic treatment was apparent under the photopic conditions. The first conditioned response appeared at the 24th trial. Discrimination between the positive red and the negative green was clear.

After giving positive responses on each of the first two presentations of green, 24 negative responses were recorded in the remaining 28 trials with this colour. The notes already made relating to numerical treatment of these figures apply here also. Over the same period the primary positive conditioning stimulus of red, constantly reirforced by shock, gave 29 positive responses out of 33 trials. Total number of trials, 99 .

\section{Specimen J. Discrimination of magenta from grey, red, blue, green .}

The experimental conditions for this specimen were identical with the last.

The positive conditioning stimulus was Magenta (filter No. 32). The differential stimuli (not followed by shock) were Grey (No. 96), Red (No. 27), Blue (No. 38A), and Green (No. 58).

The experiments were carried out over the same period as the experiments with Specimen H, and, as might be expected, with closely similar results.

Conditioned response first appeared at trial 51 on the 13 th day of actual experiment, with, however, periods of several days when no experiments were possible. This response remained uniformly strong and characteristic to the conclusion at trial 168. Of the differential stimuli, grey again produced a clear-cut result, evoking no response at any time, not even at its first presentation. Blue also gave $100 \%$ negative responses, and green gave a positive reaction once only. Red was not clearly discriminated until the 100th trial of the series.

\section{GENERAL SUMMARY AND CONCLUSIONS.}

From the experiments described in this paper it is concluded that conditioned motor responses are readily formed in Blennius pholis L. by combining the presentation of a visual stimulus with an electric shock. This has already been found to be so in B. gattorugine and in certain other fishes. Further results will be given in Part V.

Evidence of discrimination for various wave-lengths of light may be 
deduced from the resultant behaviour observed in differential conditioning, in which one colour acts as a positive conditioning stimulus reinforced by electric-shock, and the colours discriminated are similarly presented but without succeeding shock. The discriminations inferred from the results are summarised in Table III. Those aspects of the results which concern, more particularly, theories of animal learning, will be considered together with other data in a later paper.

Some of the results of the wave-length discriminations are remarkable, particularly (1) the uniform evidence of the discrimination of grey from other colours whenever they have been contrasted; (2) the behaviour towards "white" light (Specimens A and B); (3) the absence of discrimination of varying intensities of grey. The results with grey considerably strengthen the conclusions which have been drawn upon the discriminations of colours.

The results with this fish appear to suggest that it has a definite and

\section{TABLE III.}

\section{Summary of Results Relating to Wave-length Discrimination.}

The numbers in brackets indicate the filter number.

Colours for which discrimin-

ation from the positive

Colour to conditioning stimulus may

which fish be inferred from the

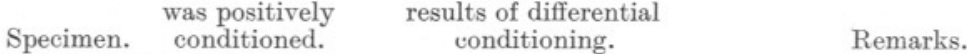

1. Scotopic (dark-adapted).
A. Green (58).
Unfiltered "white" light from gas-filled electric lamp.
No differential conditioning required; discrimination shown from the start.

\section{B. Magenta (32). \\ C. Magenta (32). \\ D. Red (27) \\ E. Blue (38A). \\ F. $\begin{aligned} & \text { Grey. } \\ & \text { (Threshold). }\end{aligned}$ \\ G. $\operatorname{Red}(70)$.}
Orange-red (71).
H. Magenta (32). Red'(27). ," , ", ",
Magenta (32), Grey (96), Siscrimination after 3 trials. Blue $(38 \mathrm{~A})$.
Orange-yellow (72).
Magenta (32), Grey (96).
Lower intensities of Grey.
down to $0.0018 \times$ Threshold $\}$
Grey, $0 \cdot 00098 \times$ Threshold- Discriminated consistently.
Yellow-green (73), Pure See text; purely numerical green (74).
Grey (96), Red (27), Blue $(38 \mathrm{~A})$, Green (58).
Discrimination after 5 trials.

$$
\text { ,, ,, } 1 \text { trial. }
$$
Not DisCRIMINATED. evidence of discrimination not satisfactory.
No differential conditioning required for grey, the others after varying amounts of differential conditioning.

2. Photopic (daylight-adapted). $\begin{array}{lll}\text { I. } & \text { Red (27). } & \begin{array}{l}\text { Green (58). } \\ \text { J. }\end{array} \\ & \text { Magenta (32). } & \text { Grey (96), Red (27), Blue } \\ & & (38 \mathrm{~A}), \text { Green (58). }\end{array}$
Discrimination after 2 trials.

No differential conditioning required for grey or blue; red and green discrim. inated after varying intervals. 
wide range of colour vision as we ordinarily speak of it, although there is no reason to suppose that we can extend this conclusion to other fishes. These experiments emphasise the difficulty of getting reliable objective evidence upon wave-length discrimination in fishes. The method is only applicable to sedentary fishes. A comparative survey of the state of knowledge upon "colour vision" in fishes which had been prepared for inclusion in this discussion has been made unnecessary by the appearance of L. H. Warner's admirable summary (3) to which reference should be made. A complete index and bibliography of the literature on the experimental study of "colour vision" in fishes is to be found in (4) compiled by the present writer in collaboration with Dr. E. S. Russell.

My thanks are due to Professor A. D. Hobson for his helpful criticism, and especially to Dr. E. J. Allen for his never-failing help and encouragement.

\section{REFERENCES.}

1. Bull, H. O. Studies on Conditioned Responses in Fishes, Part I. Journ. Mar. Biol. Assoc., N.S., Vol. XV, pp. 485-533. 1928.

2. —_ Ibid., Part II. Ibid. Vol. XVI, pp. 615-637. 1930.

3. WARner, L. H. The problem of colour vision in fishes. Quart. Rev. Biol., Vol. VI, pp. 329-348. 1931.

4. Russell, E. S., and Bull, H. O. A selected Bibliography of Fish Behaviour. Journ. du Conseil. Int. Explor. Mer., Vol. VII, pp. 255283. 1932 . 